\title{
Determining the Effect of Cutting Parameters on Surface Roughness Using Genetic Algorithm
}

\author{
Zeelan Basha N*, Selva Ganesh Kumar and Endalkachew Mosisa
}

Department of Mechanical Engineering, College of Engineering and Technology, Wollega University, Post Box No: 395, Nekemte, Ethiopia

\begin{tabular}{|c|c|}
\hline Abstract & Article Information \\
\hline $\begin{array}{l}\text { The aim of present research focuses on the prediction of machining parameters that improve } \\
\text { the quality of surface finish. The surface roughness is one of the important properties of work } \\
\text { piece quality in the CNC (Computer Numerical Control) turning process. An effective } \\
\text { approach of optimization techniques genetic algorithm (GA) and response surface } \\
\text { methodology (RSM) was implemented to investigate the effect of the cutting parameters } \\
\text { such as cutting speed, feed rate, and depth of cut on the surface roughness. In this study, } \\
\text { the surface roughness is measured during turning operation at different cutting parameters } \\
\text { such as speed, feed, and depth of cut on Alumunium } 6063 \text { using coated carbide tool. The } \\
\text { second order mathematical model is developed using RSM of central composite method to } \\
\text { predict the surface roughness standards. The regression equation is solved using genetic } \\
\text { algorithm approach for optimizing the cutting parameters for minimizing surface roughness, } \\
\text { this study attempts the application of GA technique using Matlab } 8.0 \text { is recommends } \\
1.512 \mu \mathrm{m} \text { as the best minimum predicted surface roughness value for the optimal solution of } \\
\text { the cutting conditions was } 80 \mathrm{~m} / \mathrm{min}, 0.18 \mathrm{~mm} / \mathrm{rev}, 0.3 \mathrm{~mm} \text {. }\end{array}$ & $\begin{array}{l}\text { Article History: } \\
\text { Received : : } 1-10-2013 \\
\text { Revised :07-12-2013 } \\
\text { Accepted : 26-12-2013 } \\
\text { Keywords: } \\
\text { Aluminium 6063 } \\
\text { Cutting Speed } \\
\text { Genetic Algorithm } \\
\text { RSM } \\
\text { Prediction } \\
{ }^{*} \text { Corresponding Author: } \\
\text { Zeelan Basha N } \\
\text { E-mail: zeelu6@gmail.com }\end{array}$ \\
\hline
\end{tabular}

\section{INTRODUCTION}

Alumninium (Al) Alloy 6063 is a combination of magnesium and silicon as the alloying elements. It has generally good mechanical properties and is heat treatable and wieldable. Alumninium 6063 is mostly used in extruded shapes for architecture, particularly window frames, door frames, roofs, and sign frames. But some of the limitations during machining of aluminum 6063 are lower strength at elevated temperatures and limited formability affects quality of desired output (Arun et al., 2010).

Regression Equation: Computer-generated experimental designs, such as the D-optimal design, have some advantages over traditional response surface designs such as the central composite design. One major advantage is much greater flexibility in selecting response surface model types and the number of experimental runs. There are three-factor and one response surface experiment; the following second-order model is the standard model for CCD (Ilhan and Harun, 2011).

$$
Y=\beta_{0}+\beta_{1} x_{1}+\beta_{2} x_{2}+\beta_{3} x_{3}+\beta_{11} x_{1}{ }^{2}+\beta_{22} x_{2}{ }^{2}+\beta_{12} x_{1}
$$

Genetic Algorithms: The system is mainly based on a powerful optimization technique tool. GA is a part of the evolutionary algorithms that copy intelligence of nature in order to find global extremities on the given function problem (Azlan, Habibollah and Safian Sharif, 2010).
In order to ascertain the effect of geometry parameters of the tool in the surface roughness during turning RSM was used and a prediction model was developed relating to the average surface roughness (Ra) from experimental data (Suleyman, Suleyman and Erol, 2010).

The developed model can be used in the metal machining industries in order to determine the optimum cutting parameters for minimum surface roughness. Optimum cutting conditions which correspond to maximum value of surface roughness depth $(R z)$ value, were found for the cutting speed, feed rate and for the depth of cut has been achieved (IIhan and Harun, 2011).

The influence of cutting speed, feed rate and depth of cut on the surface roughness is examined. The results indicate that the feed rate is the dominant factor affecting surface roughness, which is minimized when the feed rate and depth of cut are set to the lowest level, while the cutting speed is set to the highest level. These results demonstrated that this optimization method was efficient and greatly reduced the machining cost and the design process (Ilhan and Süleyman, 2011). In this study, the effects of cutting speed, feed rate, workpiece hardness and depth of cut on surface roughness and cutting force components in the hard turning were experimentally investigated and analysis of variance were performed. 


\section{Zeelan Basha et al.,}

The best surface roughness was achieved at lower feed rate and the highest cutting speed (Hamdi et al., 2011).The results indicate that the hybrid approaches applied for modeling and optimization of the LBC process are reasonable (Amit and Vinod, 2011).

The machining parameters (cutting speed, feed rate, depth of cut, nose radius and cutting environment)are optimized with considerations of the multiple performance measures surface roughness, tool life, cutting force and power consumption. The result analysis shows the process parameters were significant (Anil and Hari, 2010). The surface roughness is measured during turning at different cutting parameters such as speed, feed, and depth of cut. Full factorial experimental design is implemented to increase the confidence limit and reliability of the experimental data. Parameter optimization in metal cutting processes is suggested for the benefits of selection of an appropriate approach (Indrajit and Pradip, 2006).

Machining with $\mathrm{CNC}$ requires that an operator select the process parameters such as feed rate, spindle speed and depth of cut, thus the process still depends on knowledge and experience. To prevent an unsatisfactory surface finish, the most common strategy involves the selection of conservative process parameters such as feed rate, spindle speed and depth of cut, which neither guarantees the achievement of desired surface finish (Suleyman, Suleyman and Erol, 2010). To overcome these problems, the various approaches has been used to predict the surface roughness by considering the optimal process parameters (Ilhan and Süleyman, 2011).

The perusal of the literature survey indicates that there are no literatures available on the cutting condition value for minimizing the surface roughness for Aluminium 6063. In this research effective optimization techniques approach response surface methodology was used to develop mathematical model and genetic algorithm was utilized for finding the optimal cutting conditions for best surface finish and also to develop the second order mathematical model for process parameters and analysis of variance measured for process parameters to ensure the significant effects.

\section{MATERIALS AND METHODS}

\section{Experimental Setup}

For different sets of machining conditions experiments are conducted in order to obtain the surface roughness. Twenty sets of experiments were conducted as per DOE (Design of Experiments).The turning operations are carried out with the coated carbide insert on Aluminium 6063.

\section{Work Piece Material}

The work piece material, Aluminium 6063 of dimensions radius $20 \mathrm{~mm}$ and perimeter is $100 \mathrm{~mm}$ considered. Its chemical compositions and hardness are tested and hardness value is found to be $43 \mathrm{HRC}$. The table below shows the chemical composition of Aluminium 6063 (Table 1).
Sci. Technol. Arts Res. J., Oct-Dec 2013, 2(4): 98-101

Table 1: Chemical Composition for Aluminium 6063.

\begin{tabular}{cl}
\hline Al 6063 & Weight (\%) \\
\hline $\mathrm{Si}$ & 0.2 to 0.6 \\
$\mathrm{Fe}$ & $0.0-0.35$ \\
$\mathrm{Cu}$ & $0.0-0.1$ \\
$\mathrm{Mn}$ & $0.0-0.1$ \\
$\mathrm{Mg}$ & $0.45-0.9$ \\
$\mathrm{Zn}$ & $0.0-0.1$ \\
$\mathrm{Ti}$ & $0.0-0.1$ \\
$\mathrm{Cr}$ & $0.1 \mathrm{Max}$ \\
Others Each & $0.05 \mathrm{Max}$ \\
\hline
\end{tabular}

\section{CNC Lathe}

The CNC Lathe is an automated machine used for machining Purpose and it has greater accuracy and productivity (Figure 1) shown below along with specification.

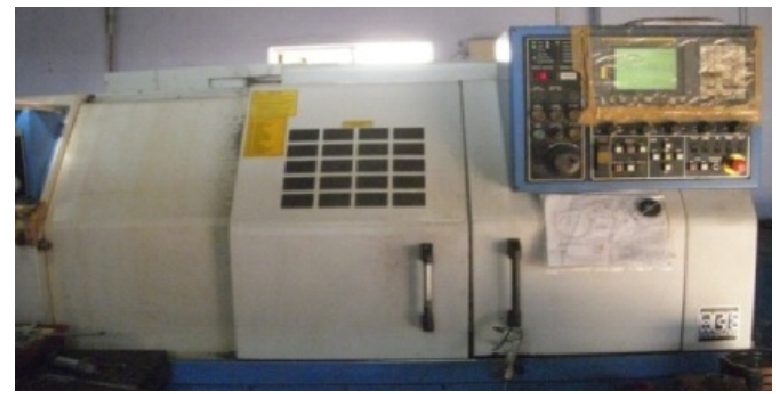

Figure 1: CNC Lathe Used for Machining.

Turning centre specification

FANUC series 0i mate-Tc

FANUC-Furic Arrow Numerical Control

Mode-Oi Mate-Tc

Turning Diameter- 250mm

Maximum speed- 3500RPM

Maximum feed $-3.00 \mathrm{~mm}$

Maximum depth of cut $-1 \mathrm{~mm}$

Turning length- $300 \mathrm{~mm}$

Chuck diameter $-200 \mathrm{~mm}$

\section{Surface Tester}

Mitutoyo SJ 201 Surf tester (Figure 2) is a surface roughness measuring device which is provided with exchangeable diamond stylus of radius of $5 \mu$, which sensing the horizontal and vertical deflection from any surface gives roughness value.

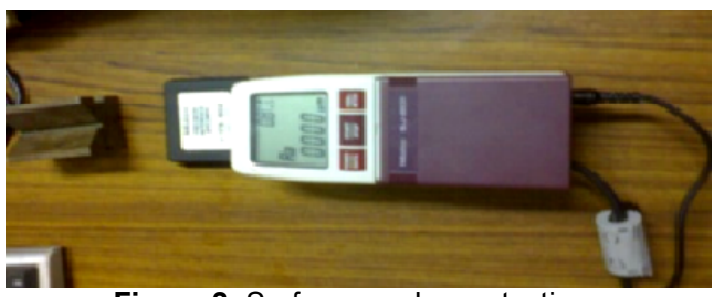

Figure 2: Surface roughness testing.

\section{Procedures of experiment}

1. Checking the adequacy of the models developed

2. Comparing the optimization results with the experimental results and finding out the percentage error between them

3. Presenting the effects of the process parameters on the mechanical properties in graphical form and analyzing the results

4. Validation 
Zeelan Basha et al.,

\section{Process Parameters and their Levels}

In this experimental analysis of process parameters has been chosen from the industry for turning process in three levels -1, 0, 1 and were represented in table 2 .

Table 2: Process parameters and their levels.

\begin{tabular}{|c|c|c|c|c|c|}
\hline SL & Cutting parameters & unit & -1 & 0 & 1 \\
\hline 1 & Cutting speed $\left(\mathrm{X}_{1}\right)$ & $\mathrm{m} / \mathrm{min}$ & 80 & 100 & 120 \\
\hline 2 & Feed rate $\quad\left(X_{2}\right)$ & $\mathrm{mm} / \mathrm{rev}$ & 0.18 & 0.27 & 0.36 \\
\hline 3 & Depth of cut & $\mathrm{mm}$ & 0.3 & 0.5 & 0.7 \\
\hline
\end{tabular}

\section{Experimental Values}

The design of experiment developed in central composite method of response surface methodology used to conduct the experiments and develop the mathematical model for prediction of optimal cutting parameters and surface roughness (Ra) (Table 3 ). The parameters are: Input parameters:

$X 1=$ cutting speed $\mathrm{m} / \mathrm{min}$

$\mathrm{X} 2=$ feed rate $\mathrm{mm} / \mathrm{rev}$

$\mathrm{X} 3=$ depth of cut $\mathrm{mm}$

Output parameter:

Surface roughness $\mu \mathrm{m}$

Table 3: Experimental values with responses.

\begin{tabular}{ccccc}
\hline \multicolumn{5}{c}{ Cutting parameter (Actual values) } \\
\hline $\begin{array}{c}\text { Cutting } \\
\text { speed } \\
\mathbf{m} / \mathbf{m i n}\end{array}$ & $\begin{array}{c}\text { Feed } \\
\text { rate } \\
\mathbf{m m} / \mathbf{r e v}\end{array}$ & $\begin{array}{c}\text { Depth of } \\
\text { cut } \\
\mathbf{m m}\end{array}$ & $\begin{array}{c}\text { Surface } \\
\text { roughness } \\
\text { Ra(Exp) }\end{array}$ & $\begin{array}{c}\text { Surface } \\
\text { roughness } \\
\text { Ra (Pred) }\end{array}$ \\
\hline 120 & 0.18 & 0.7 & 2.5 & 3.6 \\
133.6359 & 0.27 & 0.5 & 2.7 & 4.7 \\
100 & 0.27 & 0.163641 & 1.89 & 3.52 \\
100 & 0.27 & 0.5 & 1.91 & 3.44 \\
100 & 0.421361 & 0.5 & 1.85 & 4.3 \\
100 & 0.27 & 0.5 & 1.62 & 3.4 \\
80 & 0.18 & 0.3 & 1.66 & 2.3 \\
100 & 0.27 & 0.836359 & 1.86 & 3.44 \\
120 & 0.36 & 0.7 & 1.92 & 4.54 \\
80 & 0.36 & 0.3 & 1.71 & 3.43 \\
80 & 0.18 & 0.7 & 1.69 & 2.55 \\
66.36414 & 0.27 & 0.5 & 1.54 & 2.6 \\
80 & 0.36 & 0.7 & 1.83 & 3.42 \\
120 & 0.36 & 0.3 & 2.38 & 4.83 \\
120 & 0.18 & 0.3 & 2.45 & 3.76 \\
100 & 0.118639 & 0.5 & 1.89 & 2.6 \\
100 & 0.27 & 0.5 & 1.95 & 3.44 \\
100 & 0.27 & 0.5 & 1.9 & 3.44 \\
100 & 0.27 & 0.5 & 1.93 & 3.44 \\
100 & 0.27 & 0.5 & 1.89 & 3.44 \\
\hline & & & &
\end{tabular}

\section{Regression Equation}

The second order mathematical model is developed using the experimental values and responses to predict the surface roughness. Regression equations were formed using design expert 8.0 software for surface roughness $R a(Y)$ is

surface roughness $=0.36898-0.010530^{*} x(1)+5.98023^{*} \times(2)+$ $2.04872^{*} x(3) 0.058333^{*} x(1)^{*} x(2)-0.017500^{*} x(1)^{\star} x(3) 2.91667$ ${ }^{*} x(2)^{*} x(3)+0.000254063^{*} x(1)^{*} x(1)+1.63417^{*} x(2)^{*} x(2)+0.3751$ $1^{*} x(3)^{*} x(3)$
Sci. Technol. Arts Res. J., Oct-Dec 2013, 2(4): 98-101

\section{Statistical Analysis}

The effects of cutting speed, feed rate, and depth of cut on surface roughness were experimentally investigated and calculated with a statistical analysis of variance (ANOVA) were performed. The ANOVAs table 4 shows that the parameter experimented have been significant effect is sufficient.

Table 4: Analysis of variance

\begin{tabular}{cccccc}
\hline \multicolumn{6}{c}{ Analysis of variance table [Partial sum of squares - Type III] } \\
\hline Source & $\begin{array}{c}\text { Sum of } \\
\text { Squares }\end{array}$ & df & $\begin{array}{c}\text { Mean } \\
\text { Square }\end{array}$ & F Value & $\begin{array}{c}\text { p-value } \\
\text { Prob }>\text { F }\end{array}$ \\
\hline $\begin{array}{c}\text { Model } \\
\text { A-cutting } \\
\text { speed }\end{array}$ & 1.686917 & 9 & 0.187435 & 12.68699 & $0.0002^{*}$ \\
$\begin{array}{c}\text { B-feed } \\
\text { rate }\end{array}$ & 0.020357 & 1 & 0.020357 & 1.377926 & 0.2677 \\
$\begin{array}{c}\text { C-depth of } \\
\text { rate }\end{array}$ & 0.007057 & 1 & 0.007057 & 0.477695 & 0.5052 \\
AB & 0.0882 & 1 & 0.0882 & 5.970024 & 0.0346 \\
AC & 0.0392 & 1 & 0.0392 & 2.653344 & 0.1344 \\
BC & 0.02205 & 1 & 0.02205 & 1.492506 & 0.2498 \\
A $^{\wedge} 2$ & 0.148835 & 1 & 0.148835 & 10.07425 & 0.0099 \\
B^2 & 0.002525 & 1 & 0.002525 & 0.170913 & 0.6880 \\
C $^{\wedge} 2$ & 0.003245 & 1 & 0.003245 & 0.219612 & 0.6494 \\
Residual & 0.147738 & 10 & 0.014774 & & \\
Lack of Fit & 0.072405 & 5 & 0.014481 & 0.961125 & $0.5168^{*}$ \\
Pure Error & 0.075333 & 5 & 0.015067 & & \\
Cor Total & 1.834655 & 19 & & & \\
\hline
\end{tabular}

\section{RESULTS AND DISCUSSION}

Prediction Vs Actual

The graph is obtained from the experimental and prediction responses (Figure 3) using design expert software 8.0, shows the significant error in normal line.

The obtained experimental data is used to predict the surface roughness 'Ra' by developing the regression model and design of experiment. The Figure 3 Prediction Vs Experimental shows that the surface finish responses obtained from actual and prediction is lies closer in normal line, so thus the process parameters optimized for surface finish has been achieved best result.

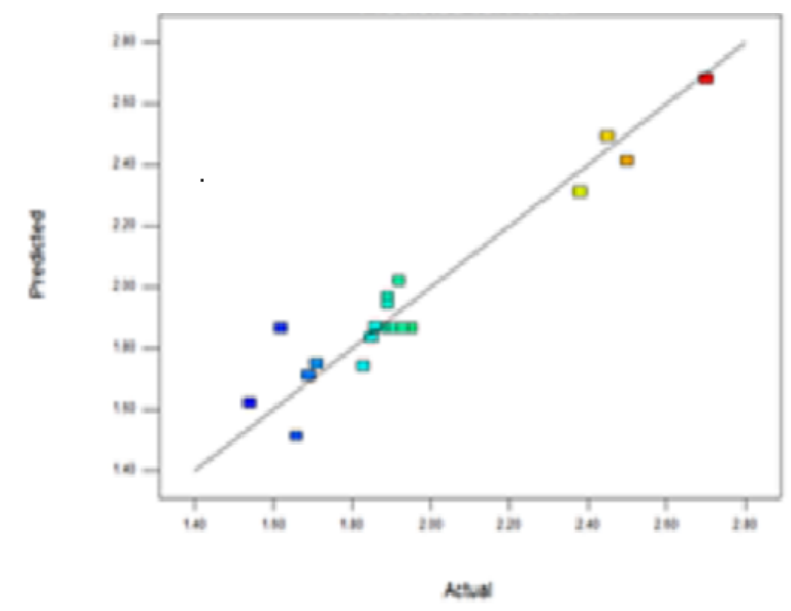

Figure 3: Prediction Vs Experimental. 


\section{Confirmation Report}

The confirmation report (Table 5) shows that the confidence level is $95 \%$ is preferred for the factors cutting speed, feed rate, depth of cut for finding the significant adequacy in analysis of variance.

Table 5: Confirmation Report.

\begin{tabular}{ccccccc}
\hline \multicolumn{2}{c}{ Confirmation Report } & \multicolumn{7}{c}{$\mathbf{n}=\mathbf{1}$} \\
\hline Two-sided & Confidence $\mathbf{= 9 5 \%}$ & \multicolumn{2}{c}{$\mathbf{n}$} \\
\hline Factor & Name & Level & Low Level & High Level & Std. Dev. & Coding \\
\hline A & cutting speed & 100 & 80 & 120 & 0 & Actual \\
\hline B & feed rate & 0.27 & 0.18 & 0.36 & 0 & Actual \\
\hline C & depth of Cut & 0.5 & 0.3 & 0.7 & 0 & Actual \\
\hline Response & Prediction & Std Dev & SE (n=1) & $\mathbf{9 5 \% ~ P I ~ l o w ~}$ & $\mathbf{9 5 \% ~ P I ~ h i g h ~}$ & \\
\hline $\begin{array}{c}\text { surface } \\
\text { roughness }\end{array}$ & \multirow{2}{*}{1.864822} & 0.121548 & 0.131268 & \multirow{2}{*}{1.572338} & \multirow{2}{*}{2.157305} & \\
\hline
\end{tabular}

\section{Best Fitness Using Genetic Algorithm Tool}

In optimization, the Plot functions best fitness preferred so it enables to display various plots of the results of the genetic algorithm considering Population 100, Current generation 52. The Figure 4 shows achieved optimization values for cutting parameters are Cutting speed is $80 \mathrm{~m} / \mathrm{min}$, Feed rate is $0.18 \mathrm{~mm} / \mathrm{rev}$, Depth of Cut is $0.3 \mathrm{~mm}$ and best fitness of surface roughness is $1.512 \mu \mathrm{m}$.

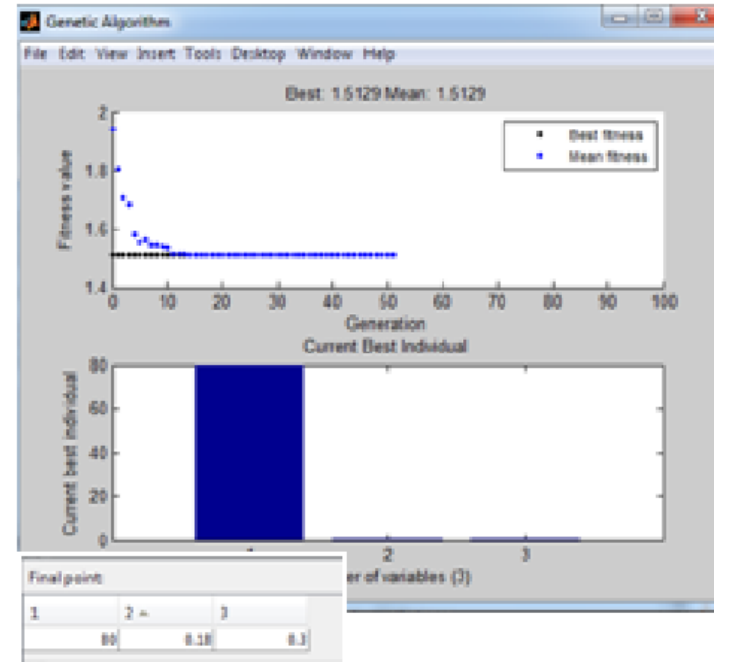

Figure 4: Surface roughness testing.

\section{CONCLUSION}

This investigation utilizing the application of genetic algorithm and recommends that optimal solution of the cutting conditions obtained on cutting speed is $80 \mathrm{~m} / \mathrm{min}$, feed rate is $0.18 \mathrm{~mm} / \mathrm{rev}$ and depth of cut $=0.3 \mathrm{~mm}$ for achieving the minimum value of surface roughness $1.512 \mu \mathrm{m}$ using matlab software 8.0 . The confirmatory test was conducted and found that the percentage of error within 0.69.

\section{REFERENCES}

Amit, S., Vinod, Y. (2011). Modeling and optimization of cut quality during pulsed laser cutting of thin Al-alloy sheet for straight profile. Optics and Laser Technology 44(1): 159168.

Anil, G., Hari, S., Aman, A. (2010). Taguchi-fuzzy multi output optimization (MOO) in high speed CNC turningof AISI P20 tool steel. Expert Systems with Applications 38(6): 6822-6828.
Arun, P.A., Alwarsamy, T., Abhinav, T and Adithya, K.C., (2012). Surface roughness prediction by response surface methodology in milling of hybrid Aluminum composites. Procedia Engineering 38: 745- 752.

Azlan, M., Habibollah, H., Safian Sharif (2010). Application of GA to optimize cutting conditions for minimizing surface roughness in end milling machining process. Expert Systems with Application 37(6): 4650-4659.

Hamdi, A., Mohamed, A.Y., Kamel Chaoui., Tarek Mabrouki., Jean-François Rigal. (2011). Analysis of surface roughness and cutting force components in hard turning with CBN tool: Prediction model and cutting conditions optimization. Measurement 45(3): 344-354.

Ilhan, A., Harun, A. (2011). Determining the effect of cutting parameters on surface roughness in hard turning using the Taguchi method. Measurement 44(9): 1697-1704.

Ilhan, A., Süleyman, N. (2011). Multi response optimization of CNC turning parameters via Taguchimethod-based response surface analysis. Measurement 45(4): 785-795.

Indrajit, M., Pradip, K. R., (2006). A review of optimization techniques in metal cutting processes. Computers and Industrial Engineering 50(1-2): 15-34.

Suleyman, N., Suleyman, Y., Erol, T., (2010). Optimization of tool geometry parameters for turning operations based on the response surface methodology. Measurement 44(3): 581-587. 